\title{
Effect of terbutaline on mucociliary clearance in asthmatic and healthy subjects after inhalation from a pressurised inhaler and a dry powder inhaler
}

Jann Mortensen, Steffen Groth, Peter Lange, Flemming Hermansen

\begin{abstract}
Background $\beta$ Agonists have been shown to increase mucociliary clearance in some studies but not all. Whether the formulation of $\beta$ agonists affects mucociliary clearance is not known but may be important as the use of dry powder inhalers increases.

Methods The effect of different methods of administration of inhaled terbutaline on mucociliary clearance and forced expiratory volume in one second $\left(\mathrm{FEV}_{1}\right)$ was assessed in 10 patients with asthma and 10 healthy subjects. Terbutaline (1 mg) was administered through a metered dose inhaler with a spacer (Nebuhaler) or a dry powder inhaler (Turbuhaler), or both treatments were given, in a four way double blind, double dummy trial. Mucociliary clearance was measured by bronchoscintigraphy.

Results Clearance of radioactivity from the lobar bronchi increased in the asthmatic patients by a median of $32 \%$ after terbutaline was given by metered dose inhaler and $55 \%$ after a combined dose of $2 \mathrm{mg}$ from both inhalers $(1 \mathrm{mg}$ from each) compared with placebo but by only $9 \%$ after $1 \mathrm{mg}$ of terbutaline was given by a dry powder inhaler. In the healthy subjects mucociliary clearance increased by $51 \%$ when terbutaline was given by a dry powder inhaler, by $66 \%$ when given by a metered dose inhaler, and by $66 \%$ when given by both inhalers combined. The effect of terbutaline on $\mathrm{FEV}_{1}$ was the same with each of the inhalers.

Conclusion Despite similar changes in $\mathrm{FEV}_{1}$ with the two formulations terbutaline increased mucociliary clearance significantly in asthmatic and healthy subjects when inhaled from a metered dose inhaler whereas when it was inhaled from a dry powder inhaler its effect was significant only in healthy subjects. The reason for the difference in asthmatic subjects is unclear, but may be associated with differences in the deposition of terbutaline.
\end{abstract}

Mucociliary clearance, one of the most important defence mechanisms in the lung, is believed to be of special importance in patients with asthma, in the defence against allergens, infections, and irritants and for clearance of airway secretions. ${ }^{1}$ It may, however, be impaired in such patients. ${ }^{2}$ Attempts have been made to develop drugs which increase mucociliary clearance. $\beta_{2}$ Adrenergic agonists have a dose dependent effect on the frequency of ciliary beats in vitro. $^{3-5}$ Studies of their effect on mucociliary clearance in humans have, however, had conflicting results. ${ }^{126-21}$ The drugs have a beneficial effect on lung function and are widely used to treat patients with asthma. They are often given by pressurised metered dose inhalers, which contain chlorofluorocarbons, although these are likely to be replaced in the future by metered dose inhalers with alternative propellants or with other portable devices for aerosolising drugs, such as dry powder inhalers. The terbutaline dry powder inhaler (Bricanyl Turbuhaler) is one such device. $^{22}$

We compared mucociliary clearance and forced expiratory volume in one second $\left(\mathrm{FEV}_{1}\right)$ in healthy subjects and patients with mild to moderate bronchial asthma after inhalation of equal doses of terbutaline from a metered dose inhaler with a spacer (Nebuhaler) and from a dry powder inhaler. Mucociliary clearance was measured by a non-invasive radioaerosol technique-bronchoscintigraphy ${ }^{6}$ - which allows visualisation of the rate of disappearance of centrally deposited radioactivity from the large airways.

\section{Methods}

SUBJECTS

Ten asthmatic subjects (five men and five women) and 10 healthy subjects (three men and seven women) participated in the study. All gave their fully informed consent and the study was approved by the medical ethics committee of Copenhagen. The median age of the asthmatic subjects was 36.5 years (range 22-69 years) and of the healthy controls 30.5 years (22-63 years). All of the asthmatic subjects had a history of repeated episodes of wheezing and dyspnoea, spontaneous peak flow variations of at least $20 \%$, and an increase of at least $15 \%$ in $\mathrm{FEV}_{1}$ after inhalation of a $\beta_{2}$ agonist. All were currently being treated with an inhaled $\beta_{2}$ agonist or steroid, or both (five with $\beta_{2}$ agonists and steroid, four with $\beta_{2}$ agonists alone, and one with steroids only). All drugs, except inhaled steroids, were withheld for the 12 hours preceding each study day. One asthmatic subject was a current smoker (30 pack years). 
Five subjects (four asthmatic and one control) had stopped smoking 10-50 years before the study (1-18 pack years). The other 14 were lifelong non-smokers.

\section{RADIOAEROSOL PROCEDURE}

Subjects inhaled an ultrasonically nebulised (by a DeVilbiss $35 \mathrm{~B}$ ) aerosol of albumin labelled with technetium-99m and isotonic saline ${ }^{6}$ according to the following technique. Inhalation, limited to a volume of $750 \mathrm{ml}$, started at residual volume. The radioaerosol was given as a bolus in the last $250 \mathrm{ml}$. The mass median aerodynamic particle diameter of the droplets from the nebuliser was $3.4 \mu \mathrm{m}$ (standard deviation $1.9 \mu \mathrm{m}$ ). The inhaled flow rate was monitored by a pneumotachograph and displayed on line on a computer screen. Subjects were instructed to keep the inhaled flow rate between 200 and $300 \mathrm{ml} /$ second. After the $750 \mathrm{ml}$ was inhaled they immediately exhaled forcefully without any holding of breath. They made 30 to 45 inhalations until about 700 counts/second was obtained from a large field of view gammacamera. ${ }^{6}$ Immediately after the radioaerosol inhalation the initial distribution of deposited particles in the lungs was visualised by a posteriorly positioned camera. Subjects were seated against the camera in a chair that was specially designed to limit movement during the five minute counting periods. For the next two hours 10 gammacamera readings were obtained at regular intervals (for each 10-15 minutes). Each bronchoscintigram was made of comparable intensity by adjusting the acquisition time to compensate for the physical decay of ${ }^{99 \mathrm{~m}} \mathrm{Tc}^{6}$ Mucociliary clearance was assessed by independent inspection of the bronchoscintigrams by two authors (JM and SG), who were unaware of which medication had been given. The assessment included counting the number of bronchi that could be identified and noting the time after inhalation when they could no longer be seen. In addition, a semiquantitative estimation of relative mucociliary clearance rates on each of the four study days was made for each subject and ranked as the slowest transport (4), second slowest (3), second fastest (2), and fastest (1).

In addition, mucociliary clearance was assessed by a conventional method. All images were recorded in $64 \times 64$ pixels and stored in the computer (General Electric Star). After correction for background and physical decay, clearance was derived from the radioaerosol retention at $\mathbf{1 2 0}$ minutes after the start in the whole lung and in the peripheral zone (fig 1) as a percentage of the initial reading.

Krypton-81m ventilation scintigraphy was used to define the lung outline and lung zones (fig 1) and to calculate a penetration ratio (the ratio of peripheral to central zone radioactivity due to $\left.{ }^{99 \mathrm{~m}} \mathrm{Tc}^{23}\right)$. The zones were created after visual inspection of the central airways in bronchoscintigrams so that the central zone ( $17 \%$ of the total pixels) covered mainly the trachea and main bronchi; the intermediate zones $(24 \%$ of the pixels) mainly lobar, segmental, and subsegmental bronchi; and the

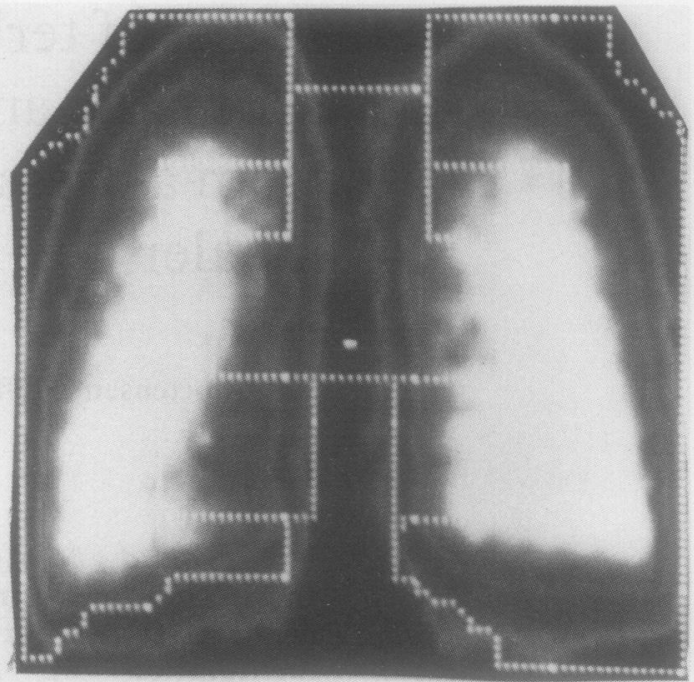
Figure 1 Central (C), right and left intermediate (I), ${ }_{81 m}^{\text {and right and left peripheral }} \mathrm{Kr}$ ventilation scintigraphy.

peripheral zones $(59 \%$ of the pixels) the more peripheral bronchial generations. Each zone contained alveoli. As indicated by ${ }^{81 \mathrm{~m}} \mathrm{Kr}$ ventilation scintigraphy the proportions of alveolar volume in the central, intermediate, and peripheral zones were about $15 \%, 33 \%$, and $51 \%$ respectively.

\section{PROTOCOL}

The effect of terbutaline sulphate on mucociliary clearance was studied by using a randomised, four part, double blind, double dummy protocol. The drug doses delivered on the four days by the metered dose inhaler and the dry powder inhaler were: placebo through both inhalers; $1 \mathrm{mg}$ of terbutaline through the metered dose inhaler and placebo through the dry powder inhaler; placebo through the metered dose inhaler and $1 \mathrm{mg}$ of terbutaline through the dry powder inhaler; and $1 \mathrm{mg}$ of terbutaline through both inhalers. The placebo metered dose inhaler canister contained the usual lubricants and chlorofluorocarbons, whereas the placebo dry powder inhaler contained nothing. In this way the amounts of propellant and lubricant inhaled were constant on the four days. The drug or placebo was inhaled immediately after the deposition of the 
${ }^{99 m}$ Tc albumin had been verified by the first bronchoscintigram. Both were administered as four puffs from the metered dose inhaler $(0.25 \mathrm{mg}$ of terbutaline per puff) attached to a pear shaped spacer (Nebuhaler, Astra) and two inhalations from the dry powder inhaler $(0.5 \mathrm{mg}$ of terbutaline per inhalation). The patients were instructed to take one deep slow inhalation from the residual volume after two puffs had been released from the metered dose inhaler into the spacer and to hold their breath for 10 seconds before exhalation. This was repeated one minute later. Inhalation from the dry powder inhaler was then performed as a forced deep inhalation from residual volume followed by holding of breath before exhalation. One minute later the inhalation was repeated.

\section{LUNG FUNCTION}

All recordings were made on a pneumotachograph (Jaeger Transfer Screen). On each study day flow volume curves were obtained before the bronchoscintigraphic investigation to ensure that the $\mathrm{FEV}_{1}$ varied by less than $15 \%$ between days. After each bronchoscintigraphic investigation-that is, 120 minutes after the inhalation of terbutaline or placebo-flow volume measurements were repeated. The highest of three technically satisfactory measurements was used.

\section{STATISTICAL ANALYSIS}

Comparison of data among the four study days was performed by Friedman analysis of variance by ranks or by the Page test for trend. ${ }^{24}$ Subsequently, matched paired data were analysed by the Wilcoxon rank sum test. Comparisons between the asthmatic subjects and the healthy subjects were made by the MannWhitney U test. Spearman's test was used for correlation analysis.

\section{Results}

LUNG FUNCTION

Median (range) baseline $\mathrm{FEV}_{1}$ was $90.5 \%$ predicted value $(41-124 \%)$ in the patients with asthma and $132 \%(109-145 \%)$ in the healthy subjects. There was no significant difference in baseline $\mathrm{FEV}_{1}$ among the four study days in either group (fig 2). In the asthmatic subjects there was a mean increase in $\mathrm{FEV}_{1}$ of 0.6 litres $(28 \%)$ above baseline 120 minutes after inhalation of terbutaline $(p<0.01)$. The increase was similar for terbutaline administered by the metered dose inhaler or the dry powder inhaler, or both. In the healthy subjects the mean increase in $\mathrm{FEV}_{1}$ after terbutaline was only $\mathbf{0 . 2}$ litres $(5 \%)$.

There was no significant difference among the penetration ratios on the four days in healthy or asthmatic subjects (table 1 ). None of the subjects had a productive cough during the examination. The median numbers of nonproductive coughs per study period in the asthmatic subjects did not differ significantly with the inhaler used: 0.5 with placebo in both inhalers, 0.3 with the drug given by metered dose inhaler, $0 \cdot 1$ with the drug given by dry

\section{$\mathrm{FEV}_{1}$ in $\%$ pred}

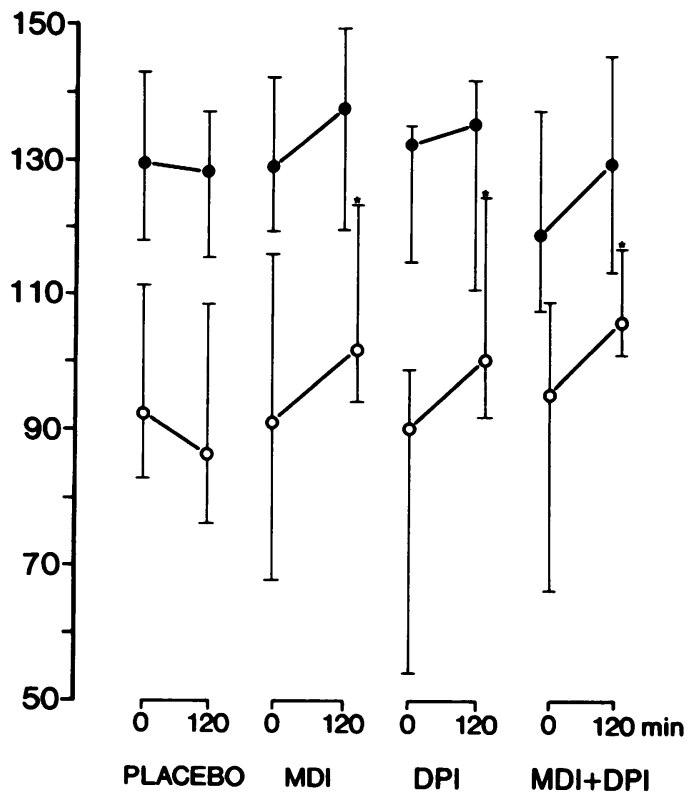

Figure 2 Median FEV, \% predicted at baseline and 120 minutes after terbutaline or placebo was given on four study days in healthy (closed circles) and asthmatic (open circles) subjects $\left({ }^{\star} p<0.05 ;\right.$ bars are upper and lower quartiles).

powder inhaler, and 0.2 with the drug given by both inhalers. Coughing in the healthy subjects was negligible (median $0 \cdot 1-0.2$ coughs per study period).

\section{BRONCHOSCINTIGRAPHY}

The trachea, main bronchi, and the five lobar bronchi were visualised in all subjects on each of the four study days. The median number of segmental bronchi visualised was 13 after treatment with placebo, drug given by metered dose inhaler, and drug given by both inhalers and 12 after drug given by dry powder inhaler in the asthmatic subjects, and 11 after treatment with placebo and drug given by metered dose inhaler and 13 after drug given by dry powder inhaler and both inhalers in the healthy subjects. The median difference between the maximum and minimum number of segmental bronchi visualised in the subjects' four bronchoscintigrams was three (range one to six) in the asthmatic subjects and two (zero to 10) in the healthy subjects.

Table 2 shows the individual estimates of mucociliary clearance of the central airways from inspection of the bronchoscintigrams. In the asthmatic subjects mucociliary clearance was similar after terbutaline given by dry powder inhaler and placebo and faster after terbutaline given by metered dose inhaler and by both inhalers. In the healthy subjects mucociliary clearance was fastest after terbutaline given by metered dose inhaler and by both inhalers, slower after terbutaline given by dry powder inhaler and slowest after placebo. The difference in mucociliary clearance between terbutaline given by metered dose inhaler and terbutaline given by both inhalers was not significant in either group. 
Table 1 Median (lower and upper quartiles) penetration ratio (peripheral/central zone activity) on four study days

\begin{tabular}{lllll}
\hline & Placebo & $\begin{array}{l}\text { Metered dose } \\
\text { inhaler }\end{array}$ & $\begin{array}{l}\text { Dry powder } \\
\text { inhaler }\end{array}$ & $\begin{array}{l}\text { Metered dose inhaler } \\
\text { plus dry powder inhaler }\end{array}$ \\
\hline Asthmatic subjects & $0.88(0.79,1.02)$ & $0.93(0.78,1.02)$ & $0.93(0.85,1.00)$ & $0.94(0.78,1.01)$ \\
Healthy subjects & $0.98(0.90,1.19)$ & $0.94(0.83,1.10)$ & $1.12(0.96,1.24)$ & $0.98(0.89,1.06)$ \\
\hline
\end{tabular}

Table 2 Rank listing of rates of disappearance of radioactivity from segmental, lobar, and main bronchi and trachea from bronchoscintigrams in asthmatic and healthy subjects (fastest clearance ranked 1, slowest ranked 4)

\begin{tabular}{|c|c|c|c|c|}
\hline $\begin{array}{l}\text { Subject } \\
\text { No }\end{array}$ & Placebo & $\begin{array}{l}\text { Metered dose } \\
\text { inhaler }\end{array}$ & $\begin{array}{l}\text { Dry powder } \\
\text { inhaler }\end{array}$ & $\begin{array}{l}\text { Metered dose inhaler } \\
\text { plus dry powder inhaler }\end{array}$ \\
\hline \multicolumn{5}{|c|}{ Asthmatic subjects } \\
\hline 1 & 3.5 & $2 \cdot 0$ & 3.5 & $1 \cdot 0$ \\
\hline 2 & $2 \cdot 0$ & $1 \cdot 0$ & $4 \cdot 0$ & $3 \cdot 0$ \\
\hline 3 & $4 \cdot 0$ & $2 \cdot 0$ & 3.0 & 1.0 \\
\hline 4 & $3 \cdot 5$ & 3.5 & $2 \cdot 0$ & 1.0 \\
\hline 5 & $4 \cdot 0$ & 3.0 & $2 \cdot 0$ & 1.0 \\
\hline 6 & 3.5 & $1 \cdot 0$ & 3.5 & $2 \cdot 0$ \\
\hline 7 & $4 \cdot 0$ & $1 \cdot 0$ & 3.0 & $2 \cdot 0$ \\
\hline 8 & $3 \cdot 0$ & 1.5 & $4 \cdot 0$ & 1.5 \\
\hline 9 & $4 \cdot 0$ & 1.5 & 3.0 & 1.5 \\
\hline 10 & $2 \cdot 5$ & $2 \cdot 5$ & $2 \cdot 5$ & $2 \cdot 5$ \\
\hline Median & $3 \cdot 5$ & $1 \cdot 8^{\star} \dagger$ & 3.0 & $1 \cdot 5^{\star} \ddagger$ \\
\hline \multicolumn{5}{|c|}{ Healthy subjects } \\
\hline 11 & $4 \cdot 0$ & 1.5 & 3.0 & 1.5 \\
\hline 12 & $4 \cdot 0$ & $2 \cdot 0$ & 3.0 & $1 \cdot 0$ \\
\hline 13 & $4 \cdot 0$ & $2 \cdot 0$ & $3 \cdot 0$ & $1 \cdot 0$ \\
\hline 14 & $4 \cdot 0$ & $2 \cdot 5$ & $1 \cdot 0$ & $2 \cdot 5$ \\
\hline 15 & $4 \cdot 0$ & 1.0 & $2 \cdot 5$ & $2 \cdot 5$ \\
\hline 16 & $4 \cdot 0$ & $1 \cdot 0$ & $2 \cdot 5$ & $2 \cdot 5$ \\
\hline 17 & $4 \cdot 0$ & 1.5 & 3.0 & 1.5 \\
\hline 18 & $4 \cdot 0$ & $2 \cdot 0$ & $3 \cdot 0$ & $1 \cdot 0$ \\
\hline 19 & $4 \cdot 0$ & 1.5 & 3.0 & 1.5 \\
\hline 20 & $3 \cdot 5$ & $2 \cdot 0$ & 3.5 & $1 \cdot 0$ \\
\hline Median & $4 \cdot 0$ & $1 \cdot 8 \star \dagger$ & $3 \cdot 0 \star \star$ & $1 \cdot 5^{\star} \dagger$ \\
\hline
\end{tabular}

${ }^{\star} \mathrm{p}<0.01$ compared with placebo.

$\dagger \mathrm{p}<0.05$ compared with dry powder inhaler, $\ddagger \mathrm{p}<0.01$ compared with dry powder inhaler.

Table 3 Last time (minutes) at which the lobar bronchi (mean for five lobar bronchi) were seen in asthmatic and healthy subjects

\begin{tabular}{|c|c|c|c|c|}
\hline $\begin{array}{l}\text { Subject } \\
\text { No }\end{array}$ & Placebo & $\begin{array}{l}\text { Metered dose } \\
\text { inhaler }\end{array}$ & $\begin{array}{l}\text { Dry powder } \\
\text { inhaler }\end{array}$ & $\begin{array}{l}\text { Metered dose inhaler } \\
\text { plus dry powder inhaler }\end{array}$ \\
\hline \multicolumn{5}{|c|}{ Asthmatic subjects } \\
\hline 1 & 77 & 56 & 98 & 25 \\
\hline 2 & 78 & 51 & 114 & 90 \\
\hline 3 & 120 & 37 & 84 & 57 \\
\hline 4 & 111 & 102 & 45 & 48 \\
\hline 5 & 114 & 81 & 33 & 24 \\
\hline 6 & 114 & 69 & 120 & 84 \\
\hline 7 & 120 & 24 & 92 & 30 \\
\hline 8 & 57 & 46 & 96 & 44 \\
\hline 9 & 120 & 16 & 24 & 18 \\
\hline 10 & 108 & 120 & 120 & 120 \\
\hline Median & 113 & $54^{\star}$ & 94 & $46^{\star} t$ \\
\hline \multicolumn{5}{|c|}{ Healthy subjects } \\
\hline 11 & 114 & 16 & 24 & 18 \\
\hline 12 & 105 & 78 & 93 & 42 \\
\hline 13 & 105 & 37 & 48 & 34 \\
\hline 14 & 114 & 37 & 28 & 39 \\
\hline 15 & 120 & 66 & 84 & 93 \\
\hline 16 & 111 & 51 & 72 & 75 \\
\hline 17 & 120 & 33 & 57 & 37 \\
\hline 18 & 111 & 22 & 31 & 16 \\
\hline 19 & 84 & 28 & 42 & 28 \\
\hline & 45 & 24 & 54 & 22 \\
\hline Median & 111 & $35 \star \ddagger$ & $51^{\star}$ & $36 * \dagger$ \\
\hline
\end{tabular}

${ }^{\star} \mathrm{p}<0.01$ compared with placebo.

$\dagger_{\mathrm{p}}<0.05$ compared with dry powder inhaler, $\ddagger \mathrm{p}<0.01$ compared with dry powder inhaler.

Table 3 gives the times the lobar bronchi were last seen in the bronchoscintigrams. The times for the asthmatic patients and healthy subjects were similar apart from the longer time for the asthmatic patients after terbutaline given by dry powder inhaler, which approa- ched significance (94 minutes $v 51$ minutes; $\mathbf{p}=0.06$ ). The time taken to clear radioactivity from the lobar bronchi in the asthmatic patients was not significantly faster (median $9 \%$ ) after terbutaline given by the dry powder inhaler than after placebo (median $\Sigma$ (dry 


\section{Clearance at $120 \mathrm{~min}$ in $\%$ of initial deposition}
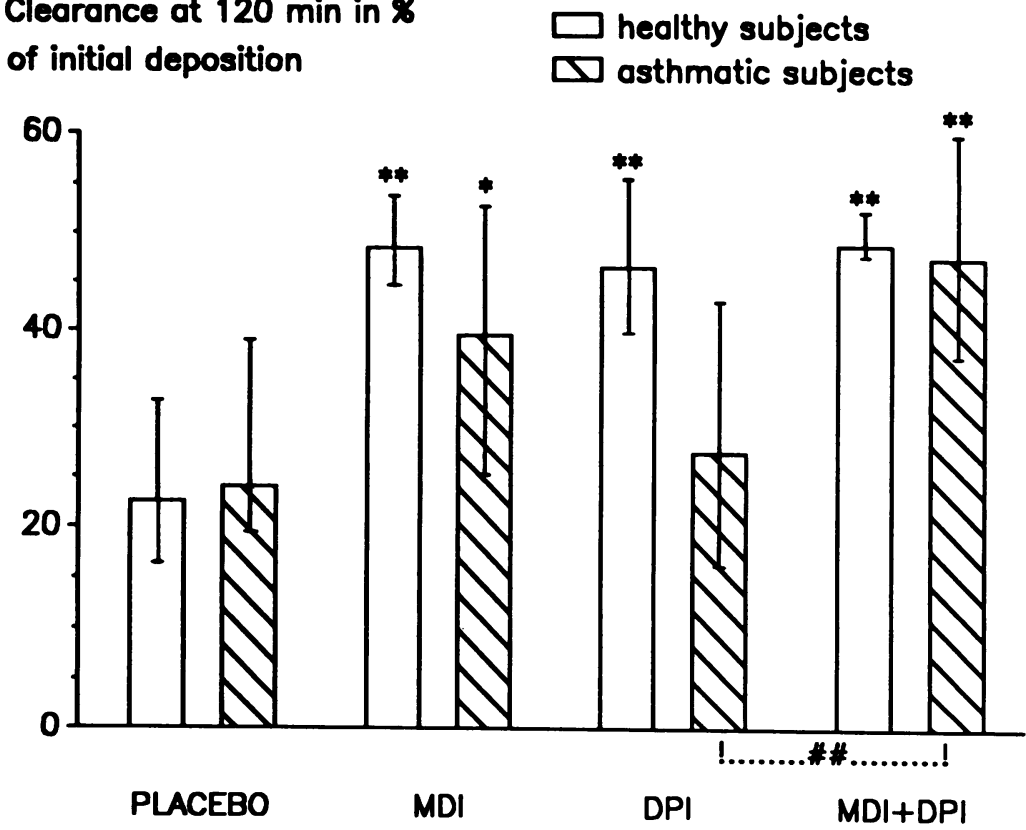

Figure 3 Percentage of initial deposition cleared at 120 minutes on four study days in healthy and asthmatic subjects $\left(\star_{p}<0.05 ;{ }^{\star} p<0.01\right.$ compared with placebo;

$\# \# p<0.01$ between terbutaline treatments; bars are median, upper and lower quartiles).

powder inhaler - placebo)/placebo $\times 100 \%$ ); this was compared with a $32 \%$ faster clearance after terbutaline given by the metered dose inhaler $(p<0.05)$ and $55 \%$ after terbutaline given by both inhalers $(p<0.05)$. In the healthy subjects the increase in clearance after terbutaline compared with placebo was $51 \%$ with the dry powder inhaler $(\mathrm{p}<0.05), 66 \%$ with the metered dose inhaler, and $66 \%$ with both inhalers $(\mathrm{p}<0.05)$.

\section{LUNG CLEARANCE AT TWO HOURS}

When total lung clearance at 120 minutes was compared in the healthy subjects and asthmatic patients (fig 3) the only significant difference was that the value after terbutaline given by dry powder inhaler in the asthmatic subjects was lower than that in healthy subjects $(\mathrm{p}<0.05)$.

The median (range) peripheral lung zone clearance at 120 minutes in the asthmatic subjects was $27 \%$ with placebo (14-52\%), $26 \%$ $(16-49 \%)$ with drug given by dry powder inhaler, $32 \%(23-43 \%)$ with drug given by metered dose inhaler, and $36 \%(17-50 \%)$ with drug given by both inhalers (page test, p < 0.05). The corresponding values in the healthy subjects were $18 \%(12-28 \%) 32 \%(25-$ $58 \%), 34 \%(24-40 \%)$, and $32 \%(25-48 \%)$ ( $\mathrm{p}<0.05$ for each drug treatment compared with placebo). Clearance was greater when terbutaline was given by metered dose inhaler than when given by dry powder inhaler in the asthmatic subjects $(p<0.05)$. The asthmatic patients showed a slightly greater peripheral lung zone clearance after placebo than healthy subjects (median $8 \% ; 95 \%$ confidence interval $1-18 \%$ ) and a lower clearance value after terbutaline given by dry powder inhaler $(9 \%$; $1-20 \%$ ).

Neither baseline $\mathrm{FEV}_{1}$ nor the change in $\mathrm{FEV}_{1}$ correlated with mucociliary clearance after placebo or with the increase in mucociliary clearance after any of the terbutaline treatments.

\section{Discussion}

The results show that the effect of terbutaline on mucociliary clearance in the asthmatic subjects was different when a metered dose inhaler and a dry powder inhaler were used. This was despite similar doses of terbutaline being administered and similar bronchodilatation being seen after terbutaline was given by both inhalers. With the doses given the plateau of the bronchodilator dose-response curve was probably reached, so that a similar degree of bronchodilatation does not necessarily imply that equal doses of terbutaline were deposited in the airways.

How can this lack of mucociliary stimulation from terbutaline given by dry powder inhaler in asthmatic patients be explained? Radioaerosol deposition pattern, numbers of coughs, baseline lung function, and amounts of inhaled aerosolised propellants and lubricants were well matched on the four study days. The fraction of drug deposited in the lung was not measured. Radiolabelled marker techniques have suggested that about $14 \%$ of the dose from a dry powder inhaler ${ }^{25}$ and $13 \%$ of the dose from a metered dose inhaler with a spacing device (Nebuhaler prototype) enter the lungs. ${ }^{26}$ The particle size of terbutaline from a metered dose inhaler when leaving the Nebuhaler has not been measured, but is likely to be slightly smaller than the mass median aerodynamic particle diameter of $3.7 \mu \mathrm{m}$ for the particles leaving the metered dose inhaler because of evaporation of propellants and trapping of the largest particles on the Nebuhaler wall. ${ }^{27}$ Terbutaline particles inhaled from a dry powder inhaler are somewhat larger $(33-50 \%$ of the particles being $<5.5 \mu \mathrm{m}$ and more than $10 \%$ being $>10 \mu \mathrm{m},{ }^{25} 28$ and they may grow hygroscopically after entering the airways. ${ }^{29}{ }^{30}$ In addition, inhalation from the metered dose inhaler with the Nebuhaler was slow compared with that from the dry powder inhaler (60 litres/minute as recommended by the manufacturer). Previous data suggest that the deposition is predominantly central in the lungs of asthmatic patients. ${ }^{25}$ These authors studied a similar inhalation procedure (with breath held for 10 seconds) to the one we used (with no holding of breath) and found a deposition of radiolabelled terbutaline with the dry powder inhaler of $39 \%, 23 \%$, and $37 \%$ in central, intermediate, and peripheral zones respectively. The relative areas (pixels) were $13 \%, 26 \%$, and $61 \%$. These figures suggest a more central distribution than that of ${ }^{99 \mathrm{~m}} \mathrm{Tc}$ albumin in our subjects $(25 \%, 39 \%$, and $36 \%$ in the respective zones). It is likely therefore, considering the probable differences in particle size and inhalation rates, that terbutaline when administered by a dry powder inhaler tends to deposit in aggregates in the large airways and oropharynx $\left(72 \%\right.$ in the oropharyn ${ }^{25}$ ) compared with a more diffuse deposition in the airways when the drug is administered by a 
metered dose inhaler and spacer $(57 \%$ in the oropharynx ${ }^{26}$ ).

If terbutaline given by a dry powder inhaler deposits predominantly in the central airways it would be expected that centrally deposited ${ }^{99 \mathrm{~m}} \mathrm{Tc}$ albumin would clear effectively. However, the peripheral mucociliary clearance was significantly (and whole lung clearance non-significantly) smaller with the dry powder inhaler than with the metered dose inhaler in the asthmatic subjects. This delayed clearance of mucus from the periphery may affect subsequent transport through central airways by failing to supply mucus at the usual rates. ${ }^{8}$

The study of mucociliary clearance was carried out by using a new bronchoscintigraphic method, which allows regional mucociliary clearance to be visualised as the movement of radioactivity in selected central bronchi. ${ }^{67}$ We also used a conventional computer based measurement of total lung clearance at two hours. The conventional method is quantitative, whereas the bronchoscintigraphic method is semiquantitative. When the effects of terbutaline and placebo in the healthy subjects were compared both methods showed a significant increase in mucociliary clearance regardless of the method of administration of terbutaline. The bronchoscintigraphic method, however, showed that the radioactivity from the central bronchi was cleared slightly faster when terbutaline was administered by a metered dose inhaler or by both inhalers than by a dry powder inhaler alone. This information was not available with the conventional method, suggesting that the bronchoscintigraphic method may provide additional data not easily obtained by the conventional method.

When administered by a metered dose inhaler $1 \mathrm{mg}$ of terbutaline doubled mucociliary clearance in both asthmatic and healthy subjects. This is consistent with previous findings in healthy subjects, ${ }^{6-14}$ but contrasts with some previous observations in asthmatic subjects. ${ }^{81521}$ Generally, no effect has been seen after doses of $\beta_{2}$ agonists corresponding to $1 \mathrm{mg}$ of terbutaline or less, whereas higher doses have caused some stimulation of mucociliary clearance. Our controlled study showed a clear stimulatory effect of only $1 \mathrm{mg}$ of inhaled terbutaline on mucociliary clearance in asthmatic patients.

The asthmatic subjects were asymptomatic at the time of examination, so it was not surprising that mucociliary clearance on the day that placebo was given was similar in the asthmatic and the control subjects as reported in some, ${ }^{17192031}$ but not all, ${ }^{12832}$ earlier studies.

In conclusion, we have shown that inhalation of $1 \mathrm{mg}$ of terbutaline from a metered dose inhaler increased mucociliary clearance significantly in asthmatic patients and healthy subjects. When the same dose was inhaled from a dry powder inhaler the increase in mucociliary clearance was smaller, despite similar bronchodilatation, and was significantly above placebo values only in healthy subjects. The smaller effect of terbutaline given by dry powder inhaler on mucociliary clearance, while having similar effects on the $\mathrm{FEV}_{1}$, is not fully understood. It may partly relate to different deposition patterns of terbutaline with the two devices.

A change in prescription from a metered dose inhaler to powder terbutaline in asthmatic subjects may be acceptable in terms of the effect on bronchodilatation, but an additional effect on mucociliary clearance may not be obtained with the dry powder formulation.

The study was supported by grants from the Danish Medical Research Council and the National Union for the Fight Against Lung Diseases. The drugs and placebo were provided by Draco (subsidiary to Astra)

1 Mossberg B. Mucociliary clearance in anti-asthmatic drug evaluation. Scand J Respir Dis 1979;103(suppl):96-101.

2 Wanner A. Clinical aspects of mucociliary transport. Am Rev Respir Dis 1977;116:73-125.

3 Iravani J, Melville GN. Mucociliary function of the respiratory tract as influenced by drugs. Respiration respiratory tract

4 Van As A. The role of selective $\beta_{2}$-adrenoceptor stimulants in the control of ciliary activity. Respiration 1974;31: 146-51.

5 Sanderson MJ, Dirksen ER. Mechanosensitive and Betaadrenergic control of the ciliary beat frequency of mammalian respiratory tract cells in culture. Am Rev Respir Dis 1989;139:432-40.

6 Groth S, Mortensen J, Lange P, Munch EP, Sørensen PG, Rossing N. Imaging of the airways by bronchoscintigraphy for the study of mucociliary clearance. Thorax 1988;43:360-5.

7 Mortensen J, Groth S, Lange P, Rossing N. Bronchoscintigraphic visualization of the acute effect of tobacco exposure and terbutaline on mucociliary clearance in exposure and terbutaline on mucocil
smokers. Eur Respir J 1989;2:721-6.

8 Foster WM, Langenback EG, Bergofsky EH. Lung mucociliary function in man: interdependence of bronchial and tracheal mucus transport velocities with lung clearance in bronchial asthma and healthy subjects. Ann Occup Hyg 1982;26:227-44.

9 Lafortuna CL, Fazio F. Acute effect of inhaled salbutamol on mucociliary clearance in health and chronic bronchitis. Respiration 1984;45:111-23.

10 Yeates DB, Aspin N, Levison H, Jones MT, Bryan AC. Mucociliary tracheal transport rates in man. $J A p p l$ Physiol 1975;396:487-95.

11 Konietzko N, Klopfer M, Adam WE, Matthys H. Die mukociliare klärfunktion der lunge unter $\beta$-adrenerger stimulation. Pneumonologie 1975;152:203-8.

12 Camner P, Strandberg K, Philipson K. Increased mucociliary transport by adrenergic stimulation. Arch Environ Health 1976;31:79-82.

13 Foster WM, Bergofsky EH, Bohning DE, Lippmann $\mathbf{M}$, Albert RE. Effect of adrenergic agents and their mode of action on mucociliary clearance in man. J Appl Physiol 1976;41:146-52.

14 Perry RJ, Smaldone GC. Effect of bronchodilators on mucociliary clearance in normal adults. Journal of Aerosol Medicine 1990;3:87-96.

15 Bateman JRM, Pavia D, Sheahan NF, Newman SP, Clarke SW. Effects of terbutaline sulphate aerosol on bronchodilator response and lung mucociliary clearance in patients with mild stable asthma. Br J Clin Pharmacol patients with mild

16 Pavia D, Sutton PP, Lopez-Vidriero MT, Agnew JE, Clarke $\mathrm{SW}$. Drug effects on mucociliary function. Eur J Respir Dis 1983;64(suppl 128):304-17.

17 Isawa T, Teshima T, Hirano T, Ebina A, Anazawa Y, Konno K. Effect of bronchodilation on the deposition and clearance of radioaerosol in bronchial asthma in remission. J Nucl Med 1987;28:1901-6.

18 Isawa T, Teshima T, Hirano T, Anazawa Y, Miki M, Konno $\mathrm{K}$, et al. Does a $\beta_{2}$-stimulator really facilitate mucociliary transport in the human lungs in vivo? Am Rev Respir Dis 1990;141:715-20.

19 Mossberg B, Strandberg K, Philipson K, Camner P Tracheobronchial clearance in bronchial asthma: response to beta-adrenoceptor stimulation. Scand J Respir Dis 1976;57:119-28.

20 Pavia D, Agnew JE, Sutton PP, Lopez-Vidriero MT, Clay MM, Killip M, et al. Effect of terbutaline administered from metered dose inhaler $(2 \mathrm{mg})$ and subcutaneously $(0.25 \mathrm{mg})$ on tracheobronchial clearance in mild asthma $\mathrm{Br} J$ Dis Chest 1987;81:361-70.

21 Felix R, Hedde JP, Zwicker HJ, Winkler C. Mukociliäre klärfunktion unter $\beta$-adrenerger stimulation mit fenoterol. Praxis Pneumologie 1978;32:777-82.

22 Persson G, Gruvstad E, Ståhl E. A new multiple dose 
powder inhaler, (Turbuhaler ${ }^{\mathrm{k}}$ ), compared with a pressurized inhaler in a study of terbutaline in asthmatics. Eur Respir J 1988;1:681-4.

23 Agnew JE, Pavia D, Clarke SW. Airways penetration of inhaled radioaerosol: an index to small airways function? Eur J Respir Dis 1981;62:239-55.

24 Siegel S, Castellan NJ. Nomparametric statistics for the behavioral sciences, 2nd ed. New York: McGraw-Hill, 1988.

25 Newman SP, Morén F, Trofast E, Talaee N, Clarke SW. Deposition and clinical efficacy of terbutaline sulphate from Turbuhaler, a new multi-dose powder inhaler. Eur Respir J 1989;2:247-52.

26 Newman SP, Morén F, Pavia D, Little F, Clarke SW. Deposition of pressurized suspension aerosols inhaled through extension devices. Am Rev Respir Dis 1981; 124:317-20.

27 Bouchikhi A, Becquemin MH, Bignon J, Roy M, Teillac A. Particle size study of nine metered dose inhalers, and their deposition probabilities in the airways. Eur Respir $J$ 1988;1:547-52.

28 Jaegfeldt H, Andersson JAR, Trofast E, Wetterlin KIL.
Particle size distribution from different modifications of Turbuhaler ${ }^{\mathrm{R}}$. In: Newman SP, Morén F, Crompton GK, eds. $A$ new concept in inhalation therapy. Proceedings of an international workshop on a new inhaler. London: Medicom, 1987:90-9.

29 Prithard JN. Particle growth in the airways and the influence of airflow. In: Newman SP, Moren F, Crompton GK, eds. $A$ new concept in inhalation therapy. Proceedings of an international workshop on a new inhaler. London: Medicom, 1987:3-24.

30 Plomp A, Fonteijn PB, Andersson JAR. Effect of relative humidity on particle size distribution from Turbuhaler. In: Newman SP, Morén F, Crompton GK, eds. $A$ new concept in inhalation therapy. Proceedings of an international workshop on a new inhaler. London: Medicom, 1987:100-3.

31 Svartengren M, Ericsson $\mathrm{CH}$, Philipson $\mathrm{K}$, Mossberg B, Camner $\mathrm{P}$. Tracheobronchial clearance in asthmadiscordant monozygotic twins. Respiration 1989;56:70-9.

32 Bateman JRM, Pavia D, Sheahan NF, Agnew JE, Clarke SW. Impaired tracheobronchial clearance in patients with mild stable asthma. Thorax 1983;38:463-7. 